\title{
Description of Chordodes anthophorus (Gordiida) for the first time in Iran with an emphasis on scanning electron microscopy characters
}

\author{
S. MOHTASEBI ${ }^{1}$, M. J. ABBASZADEH AFSHAR ${ }^{1}$, F. TABATABAIE ${ }^{2}$, A. SCHMIDT-RHAESA ${ }^{3 *}$
}

'Department of Medical Parasitology and Mycology, School of Public Health, Tehran University of Medical Sciences, Tehran, Iran; ${ }^{2}$ School of Allied Medical Sciences, Iran University of Medical Sciences, Tehran, Iran; ${ }^{*}$ Zoological Museum, University of Hamburg, Martin-Luther-King-Platz 3, 20146 Hamburg, Germany, E-mail: andreas.schmidt-rhaesa@uni-hamburg.de

Article info

Received September 15, 2020

Accepted February 18, 2021

\section{Summary}

We report a female Chordodes anthophorus from a Giant Asian Mantis (Hierodula membranacea) for the first time from Iran. Scanning electron microscopy (SEM) was used to describe the characters and substructures precisely. We demonstrate characteristic cuticular patterns for Chordodes anthophorus. The presence of five types of areoles including simple, tubercle, crowned and circumcluster areoles and also crowned areoles with long filaments which is a common feature in females, confirm our investigation.

Keywords: Nematomorpha; Gordiida; Chordodes; Scanning electron microscopy; Iran

\section{Introduction}

Nematomorpha, commonly known as horsehair worms, parasitize terrestrial and aquatic arthropods. Approximately 360 species in the taxon Gordiida are parasites of terrestrial insects (Hanelt et al., 2005; Schmidt-Rhaesa, 2013).

These worms mature in their host, manipulate its behavior and urge them towards water, where they emerge (Thomas et al., 2000). After mating and laying eggs, the hatched larvae find aquatic invertebrates that serve as paratenic hosts. It is claimed that the terrestrial final hosts become infected by consuming the paratenic hosts. However, the direct pathways of infection are still unclear (Hanelt et al., 2005).

Knowledge on biodiversity and distribution of Nematomorpha is still fragmentary. Many records were made more or less accidentally, which results in very scattered sampling and the fact that often only single specimens are available. Identifications are based on different methods and over the years scanning electron microscopy (SEM) has replaced the light microscopical investigation of cuticular fragments. Molecular barcoding becomes more and more important (e.g. Chiu et al., 2011, Hanelt et al., 2015), but the database still includes few species. Therefore, new records, especially from new or scarcely sampled locations, should document specimens as good as possible.

About 100 species belong to the genus Chordodes, this is the largest genus in Gordiida (Nematomorpha) (Schmidt-Rhaesa, 2013; Schmidt-Rhaesa et al., 2008). Most species occur in tropical and subtropical regions (Schmidt-Rhaesa, 2013; Schmidt-Rhaesa et al., 2008). Chordodes species differ in their cuticular structure. The cuticular surface is shaped into different structures called areoles. Crown-shaped areoles with apical filaments are characteristic of the genus Chordodes. According to the species, crowned areoles may occur single, in pairs or clusters with another areolar type. Other types of areoles are those with a finger-like extension on top (= tubercle areoles), those resembling a thorn (= thorn areoles), those higher than surrounding areoles (= bulging areoles), those surrounding crowned areoles (= circumcluster areoles) and those without any of these characteristics (= simple areoles). This

\footnotetext{
$\bar{*}$ - corresponding author
} 


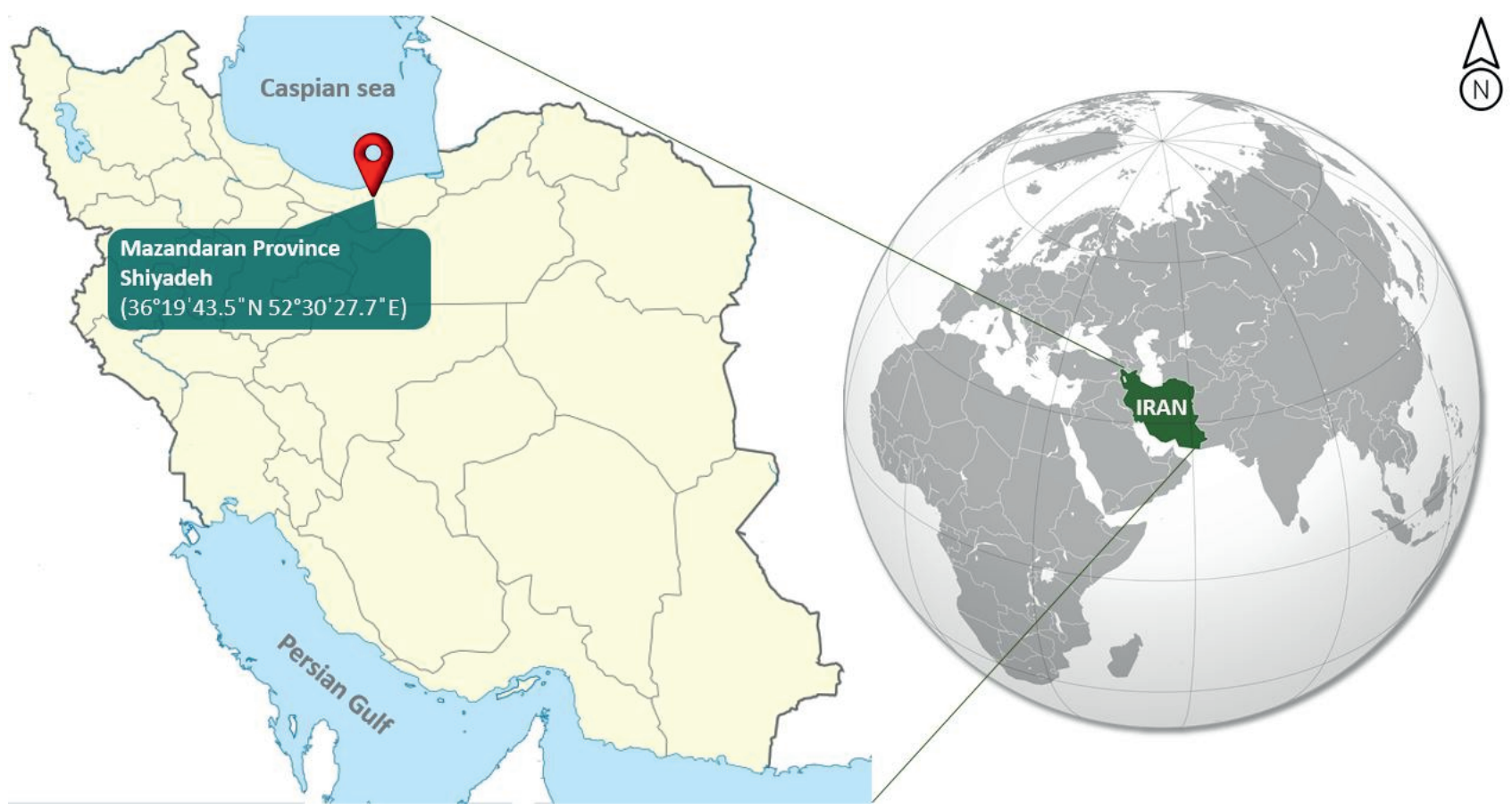

Fig. 1. Map of Iran, with the location of Shiyadeh, Mazandaran province.

terminology follows Schmidt-Rhaesa et al. (2008). Due to the complicated cuticle characters and substructures of this genus, scanning electronic microscopy (SEM) has become the standard technique for the investigation of this genus (Schmidt-Rhaesa, 2013; Schmidt-Rhaesa et al., 2008). Chordodes species parasitize different hosts, but praying mantids are the dominant host (e.g. Schmidt-Rhaesa \& Ehrmann, 2001).

We report here a new record from Iran. The nematomorph fauna of Iran is almost unknown, previously only one species, Chordodes bipilus Kirjanova, 1957 has been recorded (Kirjanova, 1957). This study describes Chordodes anthophorus Kirjanova, 1950 for the first time in Iran, including its host.

\section{Material and Methods}

During ecoparasitological studies in Shiyadeh, Mazandaran province, Iran, a female Giant Asian Mantis (Hierodula membranacea) was found infected with a horsehair worm. The worm was placed in $70 \%$ ethanol. Scanning electron microscopy (SEM) was done at the University of Hamburg. Entire pieces from the midbody region ( $1 \mathrm{~mm}$ long) were dehydrated in an increasing ethanol series, critically point dried and coated with gold in a sputter coater. The observation took place using a LEO SEM 1524 at $10 \mathrm{kV}$ and digital images were taken. The horsehair worm was deposited together with its host in the Zoological Museum in Hamburg under the accession number ZMH V13462.

\section{Ethical Approval and Informed Consent}

For this study formal consent is not required. The article does not contain any studies with human participants.

\section{Results}

\section{Chordodes anthophorus Kirjanova, 1950}

Material investigated. Single female from Shiyadeh dam shore, Mazandaran province, Iran (36 $\left.19^{\prime} 43.5^{\prime \prime} \mathrm{N} 52^{\circ} 30^{\prime} 27.7^{\prime \prime} \mathrm{E}\right)$ (Fig. 1). Collected on September 9th, 2019 by Sina Mohtasebi, Mohammad Javad Abbaszadeh Afshar, Alireza Mohtasebi and Farbod Tabatabaie.

Host. Female Giant Asian Mantis (Hierodula membranacea)

Description. The worm was $37 \mathrm{~cm}$ in length and dark brown. The anterior end is tapering, it has a whitish tip (Fig. 2B). The posterior end is slightly swollen, the cloacal opening is terminal (Fig. 2C). Five areole types are present on the cuticle. Simple oval areoles range in size from 10 to $15 \mu \mathrm{m}$ and are of slightly different elevation (Fig. 3A, B). They vary in shape (Fig. 3B, C). The simple areoles can be smooth or covered with short bristles $(2 \mu \mathrm{m})$ arranged at the center of the apical surface (Fig. 3B, C). Among the simple areoles are tubercle areoles, which contain a finger-like projection called tubercle (Fig. 3B, C). Thorn areoles were not observed. Two other types of areoles occur in clusters. Crowned areoles are decorated with filaments on top and are surrounded by $8-12$ elevated circumcluster areoles (Fig. 3D). The circumcluster areoles contain 


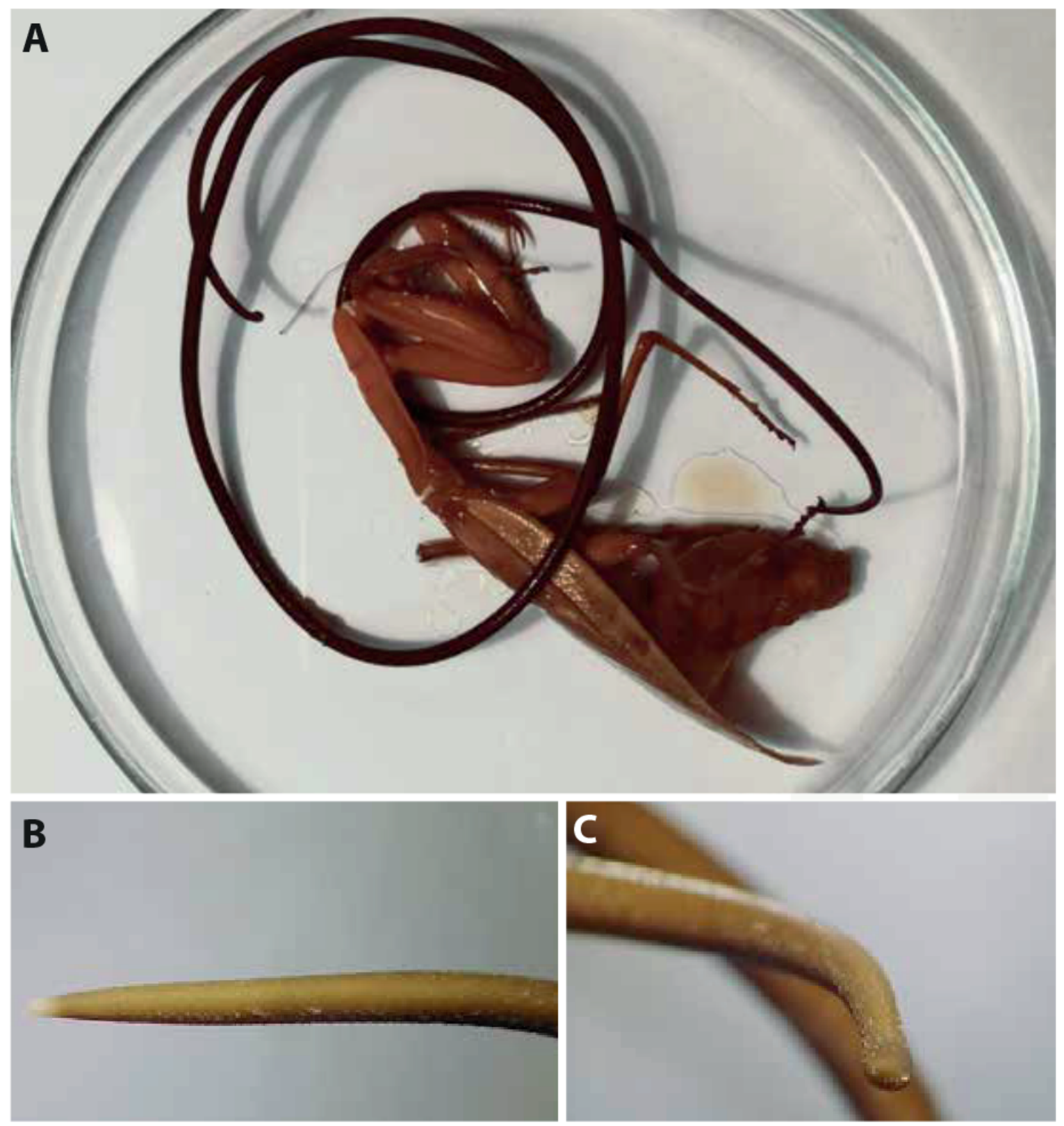

Fig. 2. Chordodes anthophorus. A. Specimen with its host, the Giant Asian Mantis (Hierodula membranacea). B. Anterior end. C. Posterior end. 

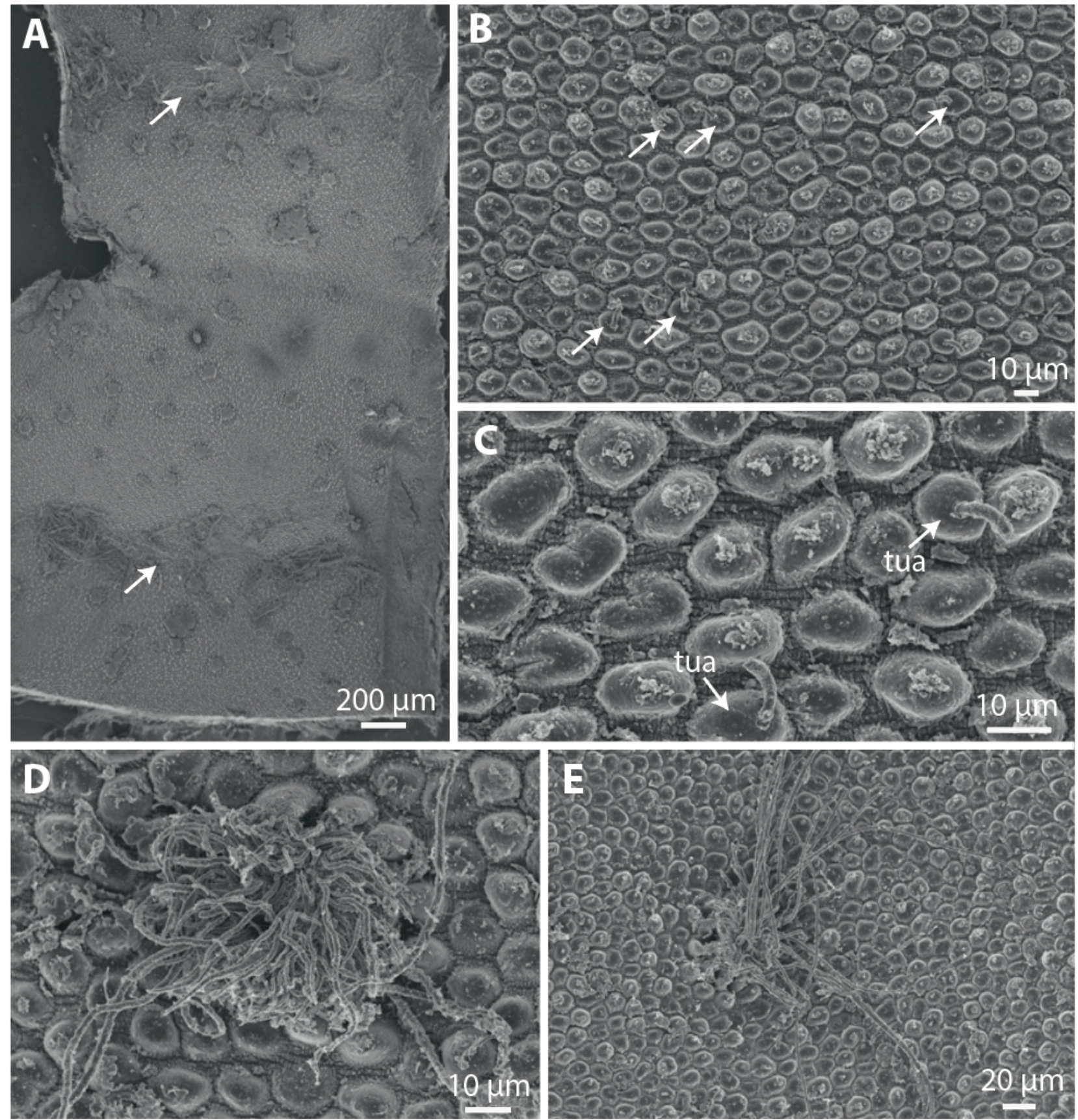

Fig. 3. Chordodes anthophorus, cuticular structure. A. Entire piece of cuticle from the entire circumference stretched flat. Crowned areoles with long apical filaments are present along the ventral and dorsal midline (arrows), clusters of crowned areoles with shorter filaments are visible on the remaining cuticle. B. Overview on the cuticle showing simple and tubercle (arrows) areoles. B. Magnification showing simple areoles with and without bristles as well as tubercle areoles (tua). C. Crowned areoles with short filaments surrounded by circumcluster areoles. D. Crowned areoles with long filaments. 
short filaments at the top. Also, another type of crowned areoles with significantly longer filaments $(80 \mu \mathrm{m})$ is present in the ventral and in the dorsal midline (Fig. 3A, E).

\section{Discussion}

Global distribution patterns of nematomorphs are very patchy, because from several countries and regions, very few records are known. Initial random records can lead to a growing awareness in undersampled regions and lead to further records. For example, between 1853 and 2004, 13 nematomorph species were recorded from entire India (Schmidt-Rhaesa \& Yadav, 2004). Until 2020, sampling activities just in the Eastern part of India raised the number to 22 species (Yadav et al., 2020).

Little information is available about the phylum Nematomorpha in Iran. Previously there was only one single report of two females of Chordodes bipilus, one from Astrabade and the other from Behbehan (province Farsistan) (Kirjanova, 1957). This species contains simple areoles with an irregular surface, tubercle and thorn areoles, crowned areole clusters composed of a pair of crowned areoles and $9-12$ circumcluster areoles. The crowned areoles contain apical filaments of two sizes, longer and thicker ones (diameter $2 \mu \mathrm{m}$ ) as well as shorter and thinner ones (diameter $1 \mu \mathrm{m}$ ) (Kirjanova, 1957). The presence of thorn areoles, of two types of apical filaments in crowned areoles and the structure of simple areoles differ from the specimen described here.

Simple, bristle and tubercle areoles, clusters composed of crowned and circumcluster areoles and the presence of very long filaments in crowned areoles on the ventral (sometimes also on the dorsal side in females) are common hallmarks of this genus (Schmidt-Rhaesa et al., 2008), but their fine structure and distribution patterns on the body cuticle are important characters for identification. The observed cuticular structures correspond well with the species $C$. anthophorus. This species was described by Kirjanova (1950) and was reinvestigated using SEM by De Villalobos et al. (2007). De Villalobos et al. describe that the simple areoles are present in two forms, with smooth surface or with a tuft of bristles, which corresponds to the newly reported specimen. De Villalobos et al. (2007) also report the absence of thorn areoles, which are present in many other Chordodes species. Finally, crowned areoles with long apical filaments were reported by De Villalobos et al. from both the ventral and the dorsal midline. In some species, this type of areoles appears to be present only along the ventral midline, but not all reports investigated the entire circumference of the worms, therefore it is not clear whether this character is absent or was just not observed. Therefore, the cuticular structure of the specimen from Iran very well corresponds with that of $C$. anthophorus as documented by De Villalobos et al. (2007).

De Villalobos et al. (2007) synonymized some other species with Chordodes anthophorus: C. anthophorus: C. aquaeductus, C. ferganensis and C. oscillates. Including these synonyms, this species is now recorded from Tajikistan, Uzbekistan, and Georgia (Schmidt-Rhaesa et al., 2008). The new report from Iran fits well in this previous distribution pattern and makes it likely that $C$. anthophorus has a broad distribution east, west and south of the Caspian Sea.

This is the first report of a host of a nematomorph species from Iran. Mantids are a common host for the genus Chordodes (Schmidt-Rhaesa, 2013; Schmidt-Rhaesa \& Ehrmann, 2001). The species Hierodula membranacea has been reported as host for Gordius verrucosus from Sri Lanka (Bell, 1885) and other or undetermined Hierodula species are reported for different Chordodes species (see summary in Schmidt-Rhaesa, 2013).

\section{Conflicts of Interest}

The authors declare no conflict of interest.

\section{Acknowledgments}

The authors would like to appreciate Mr. Alireza Mohtasebi and Dr. Majid Mohtasebi for their kind and useful help during the study.

\section{References}

BeLL, F.J. (1885): Note on a nematoid worm (Gordius verrucosus) obtained by Mr. H.H. Johnston on Kilima-njaro. Proc. Zool. Soc. London, 1885: 236

Chiu, M.-C., Huang, C.-G., Wu, W.-J., Shiao, S.-F. (2011): A new horsehair worm, Chordodes formosanus sp. n. (Nematomorpha, Gordiida) from Hierodula mantids of Taiwan and Japan with redescription of a closely related species, Chordodes japonensis. ZooKeys, 160: 1 - 22. DOI: 10.3897/zookeys.160.2290

De Villalobos, C., Zanca, F., Spiridonov, S. (2007): Fine morphology of the cuticle surface of Chordodes anthophorus and reinterpretation of $C$. aquaeductus, $C$. ferganensis and C. oscillatus (Gordiida Nematomorpha). Zootaxa, 1397: 39 - 45. DOI: 10.11646/ zootaxa.1397.1.5

Hanelt, B., Thomas, F., Schmidt-Rhaesa, A. (2005): Biology of the phylum Nematomorpha. Adv. Parasitol., 59: 243 - 305. DOI: 10.1016/S0065-308X(05)59004-3

Hanelt, B., Schmidt-Rhaesa, A., Bolek, M.G. (2015): Cryptic spesies of hairworm parasites revealed by molecular data and crowdsourcing of specimen collections. Mol. Phyl. Evol., 82: 211 - 218. DOl: 10.1016/j.ympev.2014.09.010

KIRJANOVA, E.S. (1950): Nematomorpha from the basin of the river Zeravshan. Trudy Zool. Inst. Akad. Nauka SSSR, 9: 255 - 280 (In Russian)

KIRJAnova, E.S. (1957): Two new Nematomorpha species of the genus Chordodes (Creplin, 1847) Möbius, 1855. Zool. Zh., 36: 1159 - 1166 (In Russian with French summary)

Schmidt-Rhaesa, A. (2013): Nematomorpha. In: Schmidt-RHAesa, A. (Ed) Handbook of Zoology. Gastrotricha, Cycloneuralia and 
Gnathifera. Volume 1: Nematomorpha, Priapulida, Kinorhyncha and Loricifera. Berlin: De Gruyter, pp. 29 - 145

Schmidt-Rhaesa, A., EHRMAnN, R. (2001): Horsehair worms (Nematomorpha) as parasites of praying mantids with a discussion of their life cycle. Zool. Anz., 240: 167 - 179. DOI: 10.1078/0044-5231-00014

Schmidt-Rhaesa, A., Yadav, A. (2004): First report of Chordodes cf. furnessi (Nematomorpha) from a praying mantid in India with a note on Indian nematomorph species. Current Sci., 86: 1023 - 1027 Schmidt-Rhaesa, A., De Villalobos, L.C., Zanca, F. (2008): Summary of Chordodes species (Nematomorpha, Gordiida), with a discussion of their diagnostic characters. Verh. Naturwiss. Ver. Hamburg, 44: 37 - 114

Yadav, A.K., KhynRiam, D., Limatemuen, Schmidt-Rhaesa, A. (2021): New records of horsehair worms (Nematomorpha) from India and a summary of all known Indian species. Taxonomy, 1: 14 - 22 